\title{
Indication, Clinical Profile and Management of Bullous Disease of Lung during COVID Pandemic
}

\author{
Dr. Karunakara Padhy ${ }^{1 *}$, Dr. Nirupama Devi ${ }^{2}$, Dr. Thitta Mohanty ${ }^{3}$
}

${ }^{1}$ Director CTVS, Kalinga Hospital, A100, Infocity Greens Apartment, Sailashree Vihar, Chandrasekharpur, Bhubaneswar, Odisha 751021, India

${ }^{2}$ Professor \& HOD Biochemistry, BBMCH, Balangir, Gandhrel, Odisha 767001, India

${ }^{3}$ Associate Professor Pulmonary Medicine, SCB Medical College, Manglabag, Mangalabag, Cuttack, Odisha 753007, India

DOI: $10.36347 /$ simcr.2020.v08i10.014

| Received: 30.09.2020 | Accepted: 16.10.2020 | Published: 29.10.2020

*Corresponding author: Dr. Karunakara Padhy

\section{Abstract}

The outbreak of covid-19 pandemic has lead to a great health care challenge. Though the pathophysiology understanding has improved, but still health care workers are at greater risk. World Health Organisation (WHO) and governmental policy is focusing on covid-19 management, but non-covid patients of cardiac and lung disease need equal and sometimes more attention particularly urgent and emergency cases. In bullous disease of lung presenting with dyspnoea should not be neglected as covid patient and should be treated with proper diagnosis and management. We present six cases of bullous disease who presented with high grade dyspnoea and undergone surgical treatment with strict inclusion and exclusion criteria during this pandemic. Proper perioperative covid protocols were followed in all cases.

Keywords: Bullous disease, lung, Covid-19, Dyspnoea.

Copyright $\odot 2020$ The Author(s): This is an open-access article distributed under the terms of the Creative Commons Attribution 4.0 International License (CC BY-NC 4.0) which permits unrestricted use, distribution, and reproduction in any medium for non-commercial use provided the original author and source are credited.

\section{INTRODUCTION}

The outbreak of covid-19 disease and its expansion to 213 countries leading to the situation of pandemic is a great health care challenge. Though mortality is decreasing in recent times with more understanding of pathophysiology, the infectivity is still very high. Elderly people, immunocompromised state, COPD (chronic obstructive pulmonary disease), cardiac disease, cancer, kidney and liver failure patients are at higher risk of infection and mortality. The point of more concern is of infectivity and case fatality of health care workers (HCWs).This is a period of challenge for doctors to stratify their planning of workforce to manage both COVID-19 and Non-COVID patients. World Health Organization (WHO) and governmental policy is focusing on Covid-19 management to a great extend. But non covid patients of cardiac and lung disease also need equal and sometimes more attention particularly urgent and emergency cases. Patients presenting with dyspnoea should not be neglected or sent to covid ward without proper diagnosis and management. It is very important at this critical period for resource distribution, screening, prioritization of surgery and perioperative management [1]. This study analysed the Bullous disease patients who presented with high grade dyspnoea and rejected by many centers as covid suspect.

\section{Material And Method}

Patients coming to outpatient clinic of kalinga hospital are being screened at covid screening center for travel history, flue like symptom, fever, history of contact with covid patients and whether coming from containment area. At the outpatient clinic patients with high grade dyspnoea were advised for covid test and Computed Tomography scan (CT scan) of chest (Fig 1 $\& 2$ ). Patients with bullous disease were evaluated for possibility of benefit from surgery. Out of fifteen patients with bullous disease 6 patients were evaluated for surgery between March 2020 till July 2020. All patients evaluated with surgical profile protocol and patients above 40 years also undergone cardiac evaluation.

\section{Inclusion Criteria}

1. High grade MRC (medical Research Council) dyspnoea score (grade 4 and 5).

2. CT scan: Bullae more than one third of hemithorax or ruptured bullae and no evidence of covid (Fig-1).

3. FEV1/FVC more than $20 \%$.

4. $\mathrm{PCO} 2<50 \mathrm{~mm} / \mathrm{Hg}$.

5. Covid test (rt-PCR) - negative. 


\section{Exclusion Criteria}

1. History of infection.

2. Homogenous COPD.

3. Cor pulmonale.

4. Combined bronchiectasis.

5. Other life threatening comorbidities like severe LV dysfunction, terminal cancer, CKD on dialysis.

Two patients had spontaneous pneumothorax. Perioperative patient care was taken with minimum health care workers. All Operation theatre staff were using personal protective equipment (PPE) and N95 mask. Double lumen endotracheal tube was used for intubation. All patients had undergone bullectomy through thoracotomy. One patient was operated through midsternotomy for bilateral disease. One patient required decortications in addition to bullectomy. Video Assisted thoracoscopy surgery was avoided to prevent aerosol generation. All Bullae were stapled with Ethicon straight triple layer Stappler (Fig-3). Air leak and haemostasis were controlled during operation with utmost care to prevent re exploration. Extubation was done in Operation theatre in all patients. Post operative care was given with minimum staff. All patients were advised to practice deep breathing exercise and not allowed to cough vigorously.

\section{RESULT}

Table-1:

\begin{tabular}{|l|l|l|}
\hline Patient data & Pre operative N= 06 & Post operative N = 06 \\
\hline Mean Dyspnoea grade & 4.5 & 1.6 \\
\hline Mean FEV1 & 1.41 & Not done \\
\hline Mean PO2 & $75 \mathrm{~mm}$ of $\mathrm{Hg}$ & $87 \mathrm{~mm}$ of $\mathrm{Hg}$ \\
\hline Mean PCO2 & $42.6 \mathrm{~mm}$ of $\mathrm{Hg}$ & $39.5 \mathrm{~mm}$ of $\mathrm{Hg}$ \\
\hline Mean SPO2 & 89.5 & 94.2 \\
\hline Post operative bleeding & - & $325 \pm 75 \mathrm{ml}$ \\
\hline
\end{tabular}

Total number of patients were six. The mean age was 56.33 years with age range from 48 to 70 years. Four cases were male and two were female. The clinical profile is listed in Table-1. Dyspnoea grade of 4-5 with mean 4.5 improved to 1-2 with mean of 1.6 postoperatively. Preoperative FEV1 was 1.12-1.82 liters with mean of 1.41 liters. Preoperative PCO2 was 39 $48 \mathrm{~mm}$ of $\mathrm{Hg}$ with mean of $42.6 \mathrm{~mm}$ of $\mathrm{Hg}$ which became mean of $39.5 \mathrm{~mm}$ of $\mathrm{Hg}$ postoperatively. Similarly PO2 was $67-82 \mathrm{~mm}$ of $\mathrm{Hg}$ with mean of 75 $\mathrm{mm}$ of $\mathrm{Hg}$ which improved to mean of $87 \mathrm{~mm}$ of $\mathrm{Hg}$ post operatively. Oxygen Saturation increased from 89.5 to 94.2 post operatively.

Mean post operative bleeding was $325 \pm 75 \mathrm{ml}$. Mild air leak was present in 5 patients postoperatively. All patients air leak was stopped and tubes were removed. All patients discharged in $7^{\text {th }}$ to $11^{\text {th }}$ postoperative day. There was no mortality. Patient who had undergone bilateral bullectomy expired on 32 post operative day because of covid-19 infection.

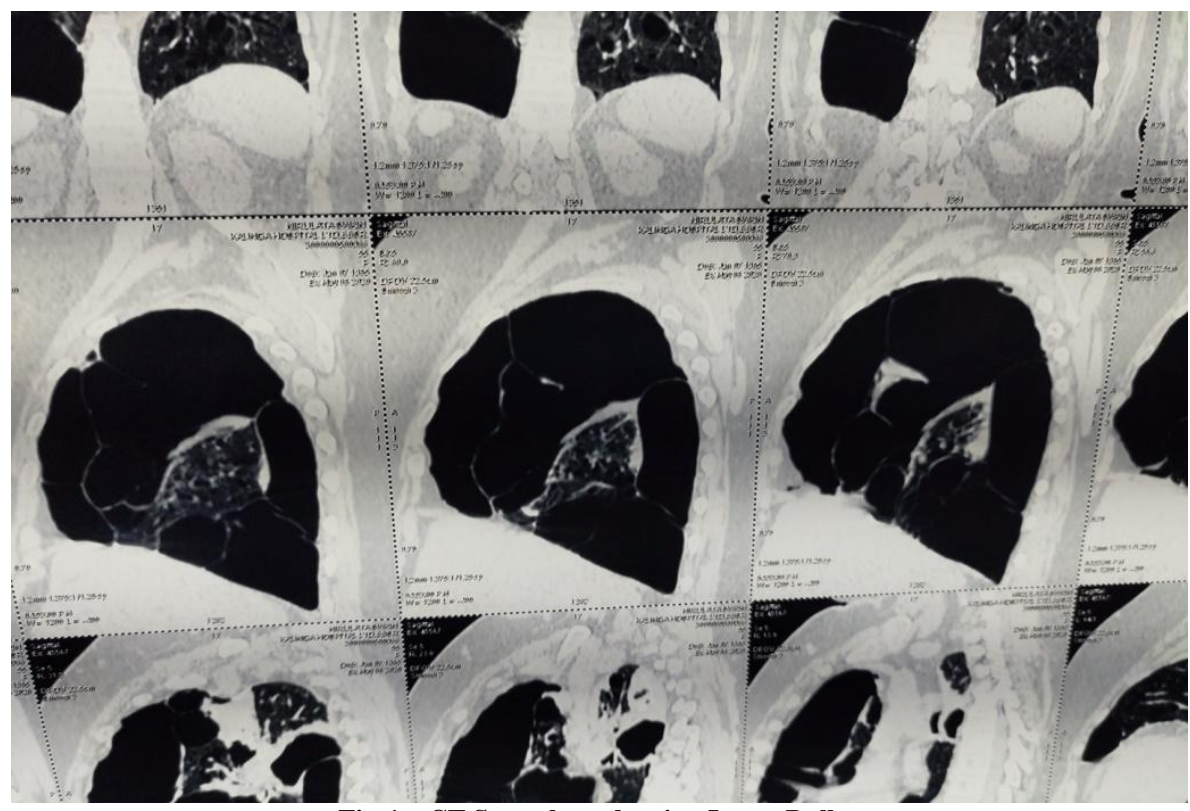

Fig-1: CT Scan chest showing Large Bullae 


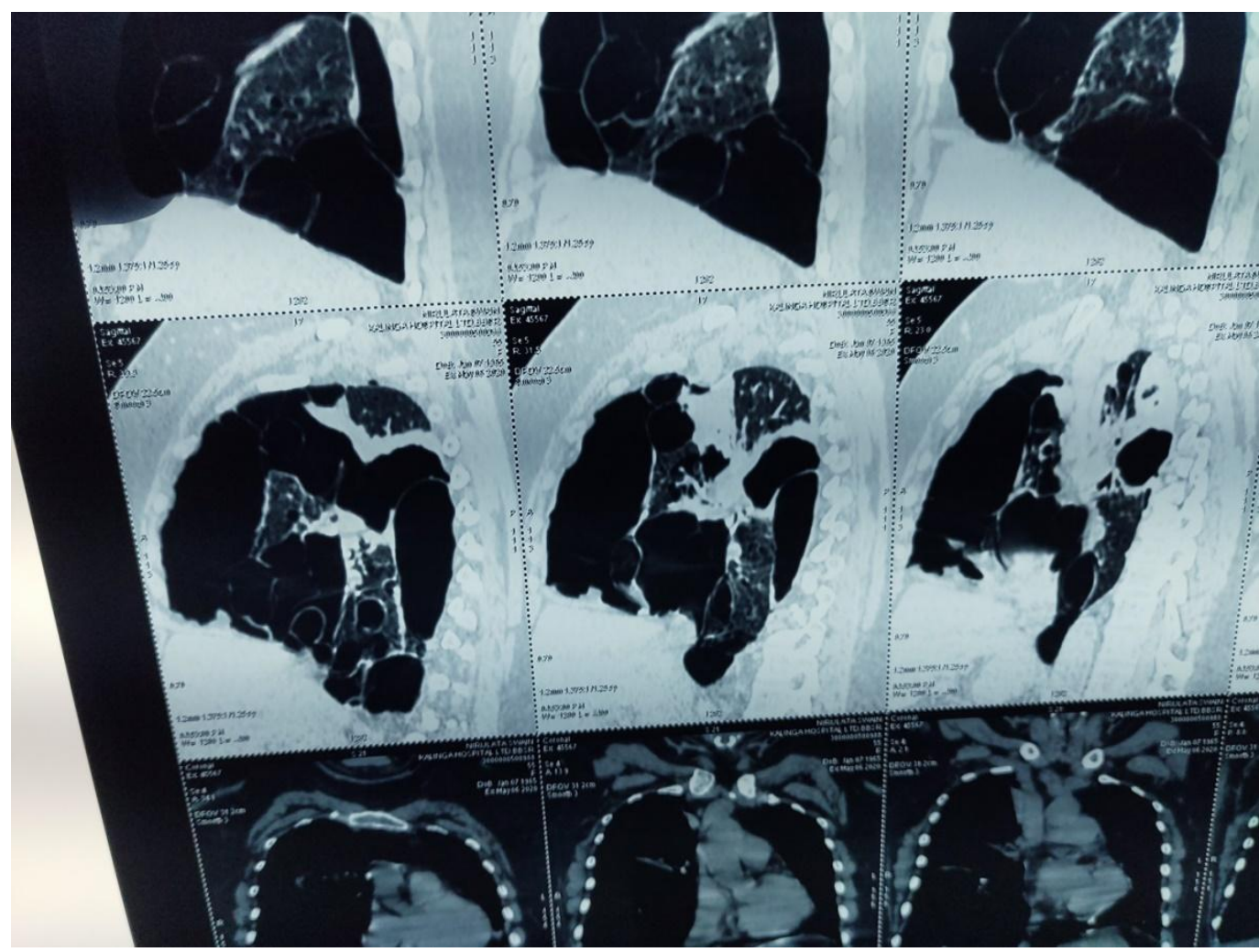

Fig-2: CT scan chest showing Multiple Bullae

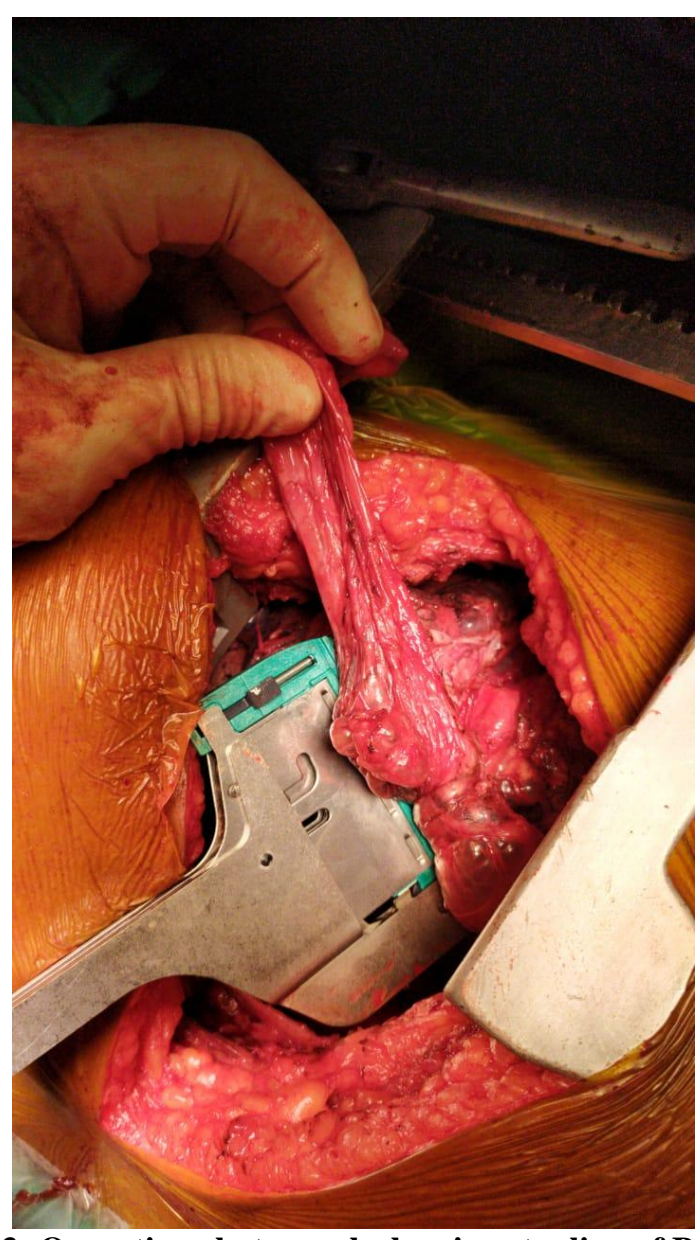

Fig-3: Operative photograph showing stapling of Bullae 


\section{DiscusSiON}

With a global concern about the covid-19 pandemic situation all the resource, man power, finance and hospital beds are getting diverted towards the care of covid-19 patients. At the same time patients developing breathing difficulty are sometimes neglected as covid suspect and denied proper non covid care. Proper strategy, proper diagnosis and treatment can bring a good outcome in non-covid emergency cases like bullous disease of lung. All of our patients were of middle age and two of them (33\%) presented with spontaneous pneumothorax. In patients with isolated bullous disease of lung with high dyspnoea grade had improvement after bullectomy [2]. The cause of dyspnoea in bullous disease is due to compression of functioning lung, increased dead space or hyperinflation with loss of elastic recoil [3]. Even patients with a well ventilated large bullae also benefit from bullectomy by reducing the volume of dead space thereby decreasing the work of breathing [4]. Patients with reduced FEV1, usually have a poor outcome but patients with large bullae with compressed lung and non-homogeneous emphysema can have good outcome $[5,6]$.

There was overall improvement of dyspnoea score to 1 and 2 in all cases. This is because of proper selection criteria. But even homogeneous emphysema with large bullae can be taken up for surgery and should not be a contraindication [7].

There was improvement of $\mathrm{PaO} 2, \mathrm{SpO} 2$ and $\mathrm{PacO} 2$ in all cases though it was not statistically significant. But may be more useful data can be obtained after 6 months and 1 year follow-up. Yasir A et al., have shown statistical improvement of all pulmonary function parameters [8]. Pulmonary function test was not performed in our cases at the time of discharge.

There was no hospital mortality in our series though studies reported from $2.1 \%-9.5 \%$ [3, 5, 6]. But post discharge covid-19 infection is a challenge which affected one of our patient. COVID infection in these groups of patients is life threatening, so proper counseling of the patients regarding this should be done.

\section{CONCLUSION}

COVID-19 though a pandemic situation and risk to health care workers is still a more critical issue. Treatment of non-covid patients should not be undermined. Dyspnoea though vital presentations of covid patients, other patients like bullous disease should not be neglected as covid suspect. Proper screening and testing for covid-19, strict inclusion and exclusion criteria for surgery, proper perioperative precaution and good surgical technique can save this group of patients with good outcome. Post operative catching of covid-19 infection should not be underestimated and properly should be explained. Proper home isolation and video consultation should be advised to prevent postoperative Covid-19 which can be life threatening.

\section{REFERENCES}

1. Leow L, Ramanathan K, Kofidis T, Tam JK, Mithiran H. Organization of thoracic surgical services during the COVID pandemic. The Surgeon. 2020 Aug 7.

2. Adeyemo AO, Andy JJ. Surgical consideration in the management of giant emphysematous bullae. J Natl Med Assoc.1987; 79(9):945-9.

3. Potgieter PD, Benatar SR, Hewitson RP, Ferguson AD. Surgical treatment of bullous lung disease. Thorax. 1981 Dec 1;36(12):885-90.

4. Pride NB, Barter CE, Hugh-Jones P. The ventilation of bullae and the effect of their removal on thoracic gas volumes and tests of overall pulmonary function. Am Rev Respir Dis. 1973; 107:83-98.

5. Fitzgerald MX, Keelan PJ, Cugell DW, Gaensler EA. Long term result of surgery for bullous emphysema. J Thorac Cardiovasc Surg. 1974; 68:566-87.

6. Gustensen J, McCormack RJM. The surgical management of bullous emphysema. J Thorac Cardiovasc Surg. 1973; 65:920-5.

7. Krishnamohan P, Shen KR, Wigle DA, Allen MS, Nichols III FC, Cassivi SD, Harmsen WS, Deschamps C. Bullectomy for symptomatic or complicated giant lung bullae. The Annals of thoracic surgery. 2014 Feb 1;97(2):425-31.

8. Lone YA, Dar AM, Sharma ML, Robbani I, Sarmast AH, Mushtaq E, Kachroo MY, Khan OM. Outcome of the surgical treatment of bullous lung disease: A prospective study. Tanaffos. 2012;11(2):27-33. 